\title{
Electro-Fenton Degradation of High Concentration Rhodamine B on Nickel Foam Cathode Catalyzed by Cucumber Bio- Templated $\mathrm{Fe}_{3} \mathrm{O}_{4} @$ PTFE
}

\author{
Chang Yang ${ }^{1}$, Huidong Xie ${ }^{2, *}$, Zhiteng Wang ${ }^{2}$, Yurong Tan $^{2}, \mathrm{Na}$ Wang $^{3}$ \\ ${ }^{1}$ Division of Laboratory and Equipment Management, Xi' an University of Architecture and \\ Technology, Xi'an, 710055, Shaanxi, China. \\ ${ }^{2}$ School of Chemistry and Chemical Engineering, Xi'an University of Architecture and Technology, \\ Xi'an, 710054, Shaanxi, China. \\ ${ }^{3}$ College of Architecture and Civil Engineering, Xi' an University of Science and Technology, Xi'an, \\ 710054, Shaanxi, China. \\ *E-mail: xiehuidong@tsinghua.org.cn
}

doi: $10.20964 / 2021.01 .54$

Received: 21 September 2020 / Accepted: 14 November 2020 / Published: 30 November 2020

Electro-Fenton technology has a great advantage in the treatment of high concentration refractory organic wastewater. In this paper, nickel foam was used as the cathode and cucumber bio-templated $\mathrm{Fe}_{3} \mathrm{O}_{4}$ was used as the catalyst to degrade rhodamine $\mathrm{B}$ by the electro-Fenton method. The active species in the degradation process were studied, and the degradation conditions were optimized. The results showed, compared with analytical reagent $\mathrm{Fe}_{3} \mathrm{O}_{4}$, the as-prepared cucumber bio-templated $\mathrm{Fe}_{3} \mathrm{O}_{4}$ has a larger specific surface area, a greater degradation efficiency, a higher concentration of generated $\bullet \mathrm{OH}$, and a lower concentration of generated $\mathrm{H}_{2} \mathrm{O}_{2}$. Hydroxyl radical is the active species during the electroFenton degradation. The degradation efficiency of $100 \mathrm{mg} / \mathrm{L}$ rhodamine B catalyzed by cucumber biotemplated $\mathrm{Fe}_{3} \mathrm{O}_{4}$ can reach $81.8 \%$ under the conditions of $\mathrm{pH} 3$ and a current of $10 \mathrm{~mA}$.

Keywords: electro-Fenton; $\mathrm{Fe}_{3} \mathrm{O}_{4}$; nickel foam; Rhodamine B; bio-templated.

\section{$\underline{\text { FULL TEXT }}$}

(C) 2021 The Authors. Published by ESG (www.electrochemsci.org). This article is an open access article distributed under the terms and conditions of the Creative Commons Attribution license (http://creativecommons.org/licenses/by/4.0/). 